\title{
Uncovering the Food Heritage based on Age Differences
}

\author{
Adilah Md Ramli', Dg Khairunisa Ahmad Sapawi', Harifah Mohd Noor², \\ Mohd Salehuddin Mohd Zahari ${ }^{3}$
}

\author{
${ }^{1}$ Faculty of Food Science and Nutrition, ${ }^{2}$ Faculty of Social Science and Humanities, \\ Universiti Malaysia, Kota Kinabalu, Sabah, Malaysia \\ ${ }^{3}$ Faculty of Hotel and Tourism Management, Universiti Teknologi MARA Puncak Alam, Selangor, Malaysia
}

m_adilah@ums.edu.my, khairunisa@ums.edu.my, harifah@ums.edu.my and salehuddinm@uitm.edu.my

Tel: +60 168317565

\begin{abstract}
The study examines national food heritage awareness in Klang Valley based on age category ( $30-35$ and $>36$ years old). Self-completed questionnaire survey is used on 676 respondents with the required age category and knowledgeable on food heritage. Differences are found on the association of National Food Heritage related to preservation, image, food identity and sustainable determinants $(p<0.05)$ in adult (>36 years old). The main criteria, 'traditional value' is mostly chosen has significant differences $(p<0.05)$. The age group's different understanding showed the view and understanding which can be used as a guide to creating an effective approachability on national food heritage.
\end{abstract}

Keywords: Awareness; Food Heritage; Age; Demographic

eISSN: 2398-4287@ 2020. The Authors. Published for AMER ABRA cE-Bs by e-International Publishing House, Ltd., UK. This is an open access article under the CC BYNC-ND license (http://creativecommons.org/licenses/by-nc-nd/4.0/. Peer-review under responsibility of AMER (Association of Malaysian Environment-Behaviour Researchers), ABRA (Association of Behavioural Researchers on Asians) and cE-Bs (Centre for Environment-Behaviour Studies), Faculty of Architecture, Planning \& Surveying, Universiti Teknologi MARA, Malaysia.

DOI: https://doi.org/10.21834/ebpj.v5i14.2245

\subsection{Introduction on Heritage}

Heritage is a broad concept that encompasses firstly the tangible assets which include natural and cultural environments, landscapes, historical sites, sites, built environments, and monument. Secondly, the intangible assets consist of collections from the past and ongoing cultural practices, knowledge, and life experiences (Farahani, Abooali, \& Mohamed, 2012). Under the intangible assets would include the intangible cultural heritage which refers to non-material objects such as language, music, dance, songs, religion, festivals and food, as well as cultural traditions, activities and customs that have been passed down through generations as part of their daily lives (Shariff \& Zakaria, 2011). Various use of intangible cultural heritage can be seen in African and Asian nations, for instance, the dance rituals and food (Graham, 2002). Traditional food is one of the UNESCO lists, which not only serves as a food heritage but is important in a strategy that led to the rise of food heritage awareness (Di Fiore, 2019). The goal of the study is to examine age-based awareness of food heritage in Klang Valley.

\subsection{Food heritage in Malaysia}

Wahid, Mohamed, and Sirat (2009) associated food heritage closely with classical and traditional foods which are continuously prepared and consumed by all generations without significant alteration from the original flavours. Food heritage can also be reflected in environmental history, belief, ideology, and food technology of society in an era (Bortolotto \& Ubertazzi, 2018). The former Heritage Commissioner of the National Heritage Department stated that heritage foods are based on two categories. The first category refers to synonymous or common foods which are become part of daily life. Whereas the second consists of foods that face extinction, in other

eISSN: 2398-4287C 2020. The Authors. Published for AMER ABRA cE-Bs by e-International Publishing House, Ltd., UK. This is an open access article under the CC BYNC-ND license (http://creativecommons.org/licenses/by-nc-nd/4.0/). Peer-review under responsibility of AMER (Association of Malaysian Environment-Behaviour Researchers), ABRA (Association of Behavioural Researchers on Asians) and cE-Bs (Centre for Environment-Behaviour Studies), Faculty of Architecture, Planning \& Surveying, Universiti Teknologi MARA, Malaysia.

DOI: https://doi.org/10.21834/ebpj.v5i14.2245 
words, foods that were once part of a culture, but are slowly dying out (Wahid et al., 2009). Malaysian favourite foods are announced and registered as National food heritage. Heritage foods divided into seven categories, namely rice, noodles, gravies and its accompanying dishes, appetisers, cake, porridge, dessert, and drinks (Negara, 2019). There are significant concerns and attention given to the preservation of traditional cuisine since it is closely related to the ingredients, preparation method, dishes and eating decorum (Choe et al., 2018). Cultural heritage is challenging to preserve and measure as it is associated with values, beliefs, behaviours, and rules of the society (Mac, 2018). The need for continuing and preserving heritage food is considered as a comparative advantage in maintaining local food culture in the face of homogenising pressures from the outside (Shariff, Mokhtar, \& Zakaria, 2008) and continuation of preserving the creation of valued products especially the traditional cuisines (UNESCO, 2008). Endorsement or certification or gazetting is one method to preserve heritage food and identity. This initiative revealed the awareness and determination of the country to preserve and safeguard their culinary heritage by certifying sites for their food throughout the country (Bessiere, 1998). In this context, the critical factor in driving the local population to protect their heritage is by cultivating awareness of their cultural heritage.

\subsection{Relationship between age and food heritage}

Concerning this study, the traditional cuisine is one of the best examples of cultural heritage which covers the unique aspects of a culture in terms of the ingredients, preparation methods, dishes, or services of foods. This type of cultural heritage is more difficult to preserve than the physical object as it concerns the values, beliefs, behaviours, and rules of the society which is difficult to measure especially among the public (Shariff et al., 2008). Moreover, the awareness and knowledge among the public in regards of traditional cuisine have increased in recent years (Hamzah, Ab Karim, Othman, \& Hamzah, 2013; Jalis, Che, \& Markwell, 2014; MD Ramli, Ahmad Sapawi, \& Mohd Zahari, 2020; Sompong \& Rampai, 2015). Age categories in this study are adult ( $>36$ years old) and young adult ( $<35$ years old) (Peterson \& Baez, 2013). Age usually relates to identity as it is often consolidated during emerging adult years compared with the early age and middle adolescence, whereby, they are still in the development stage (Schwartz, 2016). This important, especially in food identity for one nation and, would the main reason this study is being studied.

\subsection{Methodology}

This study intends to explore food heritage and its effects on food identity from the public point of view, specifically, based on respondents' demographic profiles. Quantitative method was used to gather all necessary information.

\subsection{Sampling and population plan}

The information needed for this study was gathered from 676 respondents in Klang Valley area using a self-completed questionnaire survey. The public was the study's targeted population, consist of Malay, Chinese and Indian ethnic groups. Owing to the widely distributed populations of Malay, Chinese and Indian, the researcher could not collect the desired information throughout the country. The sample of the population was selected among the public residents of Klang Valley (Lembah Klang), which comprises of the Federal Territory of Kuala Lumpur, Putrajaya, the Petaling district in Selangor (Shah Alam, Petaling Jaya and Subang Jaya), Gombak, Klang and Hulu Langat and their suburbs and adjoining cities and towns (Kamaruddin, Osman \& Pei, 2017). To get better insights into the required information respondents were selected based on their states of upbringing, age within 30-35 years and > 36 years old and knowledgeable on food heritage.

\subsection{Research instrument}

The survey questionnaire is structured into four major sections. This study only analysis section A consists of a definition, media information, the authority, type, and criteria of food heritage were adapted and modified from previous researchers (Ramli, Zahari, Halim \& Aris, 2016). A nominal scale is used to gather the demographic background; meanwhile, the application of the ordinal scale is to measure the awareness and knowledge of food heritage among the respondents.

The survey data obtained was tested for reliability and validity. In this study, the researcher employed internal consistency reliability, using Cronbach's Alpha where this type of reliability is used to assess a summated scale where several statements (items) are summed to form a total score for a construct. An acceptable level of reliability indicates that respondents are consistently answering the questions.

\subsection{Findings}

Test for the reliability of the questionnaire has been done using Cronbach's alpha, with results of 0.837 , which is an acceptable level for this study. The data are then analysed using descriptive analysis such as frequency and percentages. The significance value using chisquare under nonparametric statistic as the data is not normal $(p<0.05)$ the demographic profile and the awareness on food heritage are being analysed. Discussion of the result and comparison with past literature would conclude the findings to answer the study's objective. 


\subsection{Respondents' profile}

In this study, frequency and descriptive analysis were conducted on the respondent's demographic profile. Table 1 presents the descriptive result of the respondents' profiles. As reported in the table, the majority of respondents were female, at age 30-35 as a young adult $(n=186)$ and $>36$ age as an adult $(n=204)$. Based on ethnicity, the majority were Malay with young adult $(n=288)$ and adult $(n=234)$. In term of professions, the majority were working in the private sector with young adult $(n=137)$ and adult $(n=162)$. As for the educational background, the majority were diploma holders with young adults $(n=244)$ and adults $(n=118)$.

Table 1: Demographic Background

\begin{tabular}{|c|c|c|}
\hline \multirow{2}{*}{$\begin{array}{l}\text { Demographic } \\
(n=676)\end{array}$} & \multicolumn{2}{|c|}{ Age group } \\
\hline & $30-35$ & $>36$ \\
\hline \multicolumn{3}{|l|}{ Gender } \\
\hline Male & 152 & 134 \\
\hline Female & 186 & 204 \\
\hline \multicolumn{3}{|l|}{ Ethnicity } \\
\hline Malay & 288 & 234 \\
\hline Chinese & 26 & 52 \\
\hline Indian & 18 & 45 \\
\hline Others & 6 & 7 \\
\hline \multicolumn{3}{|l|}{ Profession } \\
\hline Government servant & 129 & 109 \\
\hline Private servant & 137 & 162 \\
\hline Professional & 10 & 28 \\
\hline Student & 52 & 3 \\
\hline Other & 10 & 36 \\
\hline \multicolumn{3}{|l|}{ Education } \\
\hline UPSR & 0 & 4 \\
\hline SRP/PMR & 1 & 21 \\
\hline SPM & 57 & 72 \\
\hline Diploma & 244 & 118 \\
\hline Degree & 36 & 76 \\
\hline Master & 0 & 33 \\
\hline $\mathrm{PhD}$ & 0 & 10 \\
\hline Others & 6 & 4 \\
\hline
\end{tabular}

\subsection{Awareness of national food heritage based on age group}

This section examines the awareness on food heritage based on the definition of food heritage, list categories of food heritage, media information, authority, association and criteria for National Food Heritage using frequencies, percentages and significant value based on chi-square to see the differences between the age groups.

\subsubsection{Definition of food heritage}

As shown in Table 2 and Figure 1, the majority of the active response to the questions are adult age (>36 years old). 'Traditional food' has been related to the highest definition of food heritage with a higher response from adult respondents $(n=314)$. They also recognise food heritage as 'food that is passed down from one generation to another', with $(n=244)$. The third definition the respondents chose is 'food that is related to cultural background' with $(n=216)$. Furthermore, 'Sensory properties' and 'Commonality' are mostly chosen by adult age respondents ( $n=191$ and 165). Meanwhile for 'celebration' with $n=143$, 'original ingredients' with $n=127$ and 'authentic cooking method' with $n=121$ show that young adult respondents (30-35 years) as their fourth, fifth and sixth definition for food heritage. Compared with adult respondents, they inclined to 'Original ingredients' with $n=209$, 'Authentic cooking method' with $n=208$ and 'Celebration' with $\mathrm{n}=202$ as their fourth, fifth and sixth definition of food heritage. 
Table 2: Definition of Food Heritage based on Age Group

\begin{tabular}{llllll}
\hline Definition & Rank & $30-35$ & Rank & $>36$ & N-value \\
& & $N=338$ & & N=338 & \\
\hline Traditional food & 1 & 229 & 1 & 314 & $0.047^{*}$ \\
Food passed down & 2 & 175 & 2 & 244 & 0.000 \\
Related to cultural back ground & 3 & 159 & 3 & 216 & 0.000 \\
Celebration & 4 & 143 & 6 & 202 & 0.000 \\
Original ingredients & 5 & 127 & 4 & 209 & 0.000 \\
Authentic cooking method & 6 & 121 & $\mathbf{5}$ & $\mathbf{2 0 8}$ & 0.000 \\
Sensory properties & 7 & 107 & 7 & 191 & 0.000 \\
Commonality & 8 & 64 & 8 & 165 & 0.000 \\
$N=676{ }^{*}$ Not significant $(p>0.05)$ & & & & &
\end{tabular}

Table 2 also shows significant value for each definition. However, 'Traditional food' is the only definition has no significant difference $(p>0.05)$ between adults and young adults with $p$-value $=0.047$ by showing both age categories have a mutual agreement that 'traditional food' is best for defining food heritage.

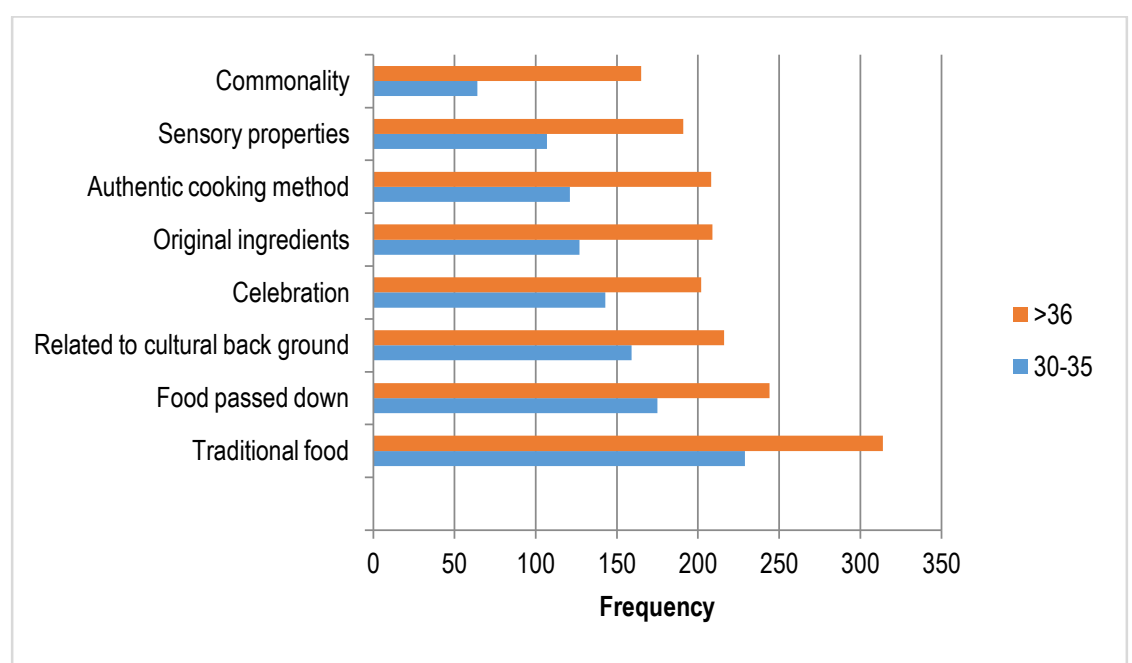

Figure 1: Definition of Food Heritage based on Age

\subsubsection{The categories of food heritage recognition based on age}

Traditional food under food heritage list can be divided into nine categories such as rice-based, dessert, gravies and accompaniments, drinks, noodles, appetisers, and cakes. As shown in Table 3 and Figure 2, the most identified food category as food heritage and traditional food is the rice-based category with an overall frequency of $19.87 \%$ with young adults at age $30-35$ years old $(n=224)$ and adults at $>36$ years old $(n=187)$.

Table 3: Food heritage categories with Age

\begin{tabular}{llll}
\hline \multirow{2}{*}{ Categories } & \multicolumn{3}{c}{ Frequency } \\
& Overall (\%) & $30-35$ & $>36$ \\
\hline Rice-based & 19.87 & 224 & 187 \\
Dessert & 16.34 & 171 & 167 \\
Gravies \& Accompaniments & 15.9 & 178 & 151 \\
Drinks & 12.71 & 147 & 116 \\
Noodles & 10.1 & 112 & 97 \\
Porridge & 10.1 & 104 & 105 \\
Appetiser & 8.02 & 94 & 72 \\
Cakes & 6.96 & 83 & 61 \\
\hline
\end{tabular}

Followed by 'Dessert' category with $16.34 \%$ of young adults responding more $(n=171)$ than adults ( $n=167)$. Third food category widely affirmed is from 'Gravies and Accompaniments' with $15.9 \%$ preceded by a young adult $(n=178)$ follow by adults $(n=151)$. Drinks 
category came at fifth-most identified by young adults with $n=147$ and an adult $(n=116)$. Despite similar category overall value for 'Noodles' and 'Porridge' categories, the identified age from is different from other categories. Like other categories, "Noodles' showed that young adults could be identified more $(n=112)$ and adults $(n=97)$. However, the 'Porridge' category has shown that adults identified more $(n=105)$ than by young adults $(n=104)$. For the last two categories which are 'Appetiser' with overall $8.02 \%$ and 'Cakes' with overall $6.96 \%$. Appetiser categories with young adult $(n=94)$ and adult $(n=72)$. Lastly, 'Cakes' category was identified more by young adults $(n=83)$ than adults $(n=61)$.

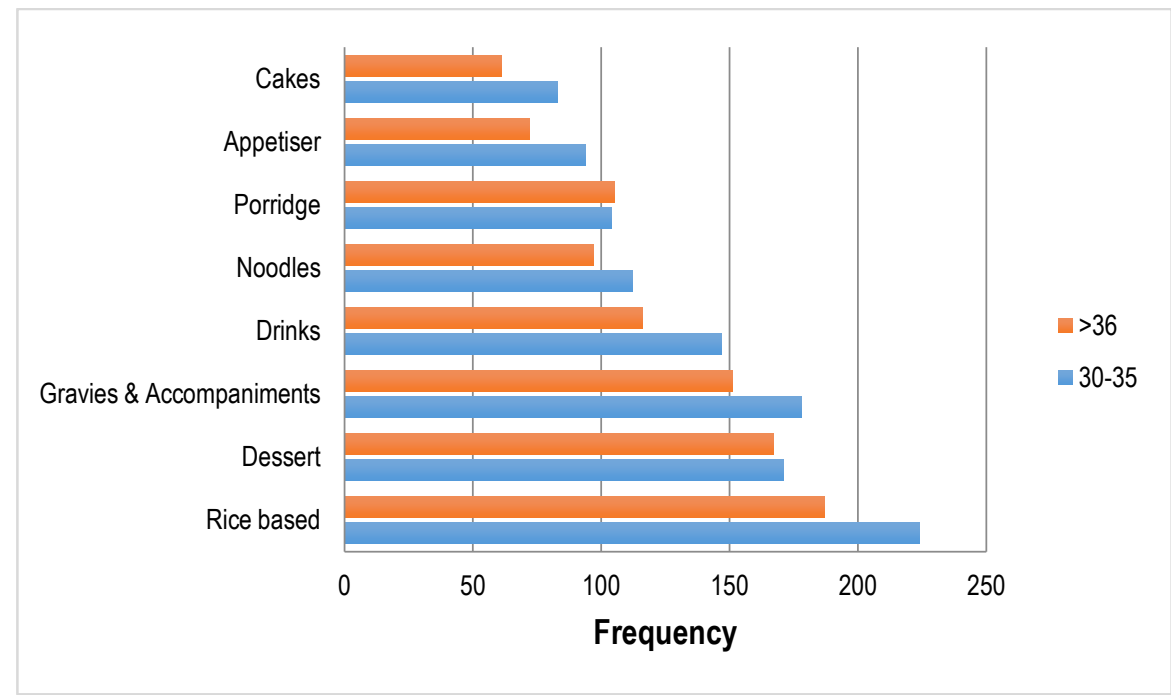

Figure 2: Categories of food heritage recognition based on Age

\subsubsection{Information on national food heritage}

Based on the finding at Table 4, both ages use electronic media such as internet, radio or television as tools finding information on National Food Heritage with young adults $(n=189)$ and adults $(n=185)$. Print media such as newspaper, magazine, or brochure as their primary referral for information with adults $(n=134)$ and young adults $(n=125$. There is no significant value $(p>0.05)$ between age as the use of both media are interchanging.

Table 4 Different type of Media with Age

\begin{tabular}{llll}
\hline & \multicolumn{3}{c}{ Age } \\
\cline { 2 - 4 } Media & $30-35$ & $>36$ & P-value \\
\hline Electronic Media & 189 & 185 & \\
Print Media & 125 & 134 & $\mathbf{0 . 7 4 9 *}$ \\
Others & 17 & 12 & \\
No Answer & 7 & 7 & \\
\hline & ${ }^{*}$ Not significant $(p>0.05)$
\end{tabular}

\subsubsection{The authority responsible}

Findings in Table 5 show that most respondents $(n=365)$ know the authority responsible for endorsing and certifying the National Food Heritage. The adult $(n=208)$ answers correctly than young adult $(n=157)$. There is a significant difference $(p<0.05)$ between both age categories due to their background education. Thus, this affects their knowledge on the matter.

Table 5 Authorities with Age

\begin{tabular}{|c|c|c|c|c|}
\hline \multirow{2}{*}{ Authority } & \multicolumn{4}{|l|}{ Age } \\
\hline & $30-35$ & $>36$ & Total & P-value \\
\hline Department of National Heritage & 157 & 208 & 365 & \\
\hline Wrong Answer & 100 & 63 & 163 & 0.000 \\
\hline Not sure & 78 & 62 & 140 & \\
\hline No Answer & 3 & 5 & 8 & \\
\hline
\end{tabular}




\subsubsection{Association national food heritage}

The criteria or determinant associated with National Food Heritage chose by respondents were 'Preservation' ( $n=472)$, 'Represent image' $(n=414)$, 'Food identity' $(n=365)$ and 'Sustainability' ( $n=307)$. Finding in Table 6 shows that there is a different opinion on criteria associated with National Food Heritage with $p=0.000(p<0.05)$ between adults and young adults. The result also shows that all criteria are adults (>36 years old) as the main respondent compared to young adults (30-35 years old). The adult $(n=271)$ has chosen the first criteria is 'Preservation' as the main association with National Food Heritage compared with young adult $(n=201)$. Secondly, the association of 'Represent image' is chosen mostly by adults $(n=236)$ than young adults $(n=178)$. Next is 'Food identity' with adults $(n=215)$ and young adults $(n=150)$, and lastly is 'Sustainability' with adults $(n=197)$ and young adults $(n=110)$ which response less than half response for both age.

Table 6 Association National Food Heritage with Age

\begin{tabular}{lllll} 
& \multicolumn{4}{l}{ Age } \\
\cline { 2 - 5 } & $30-35$ & $>36$ & Total & P-value \\
\hline Preservation & 201 & 271 & 472 & 0.000 \\
Represent Image & 178 & 236 & 414 & 0.000 \\
Food Identity & 150 & 215 & 365 & 0.000 \\
Sustainability & 110 & 197 & 307 & 0.000 \\
\hline & *Not significant $(p>0.05)$ & &
\end{tabular}

\subsubsection{The criteria for food heritage with age}

Respondents have been asked to choose which criteria of traditional food should be considered as heritage. Table 7 shows that the overall value of respondents choosing 'Traditional value' is higher than other criteria with adults ( $n=296)$ and young adults $(n=268)$. 'Originality' criteria, which placed at second, with adults $(\mathrm{n}=279)$ and young adults $(\mathrm{n}=225)$. Third highest is 'Authentic flavour' with adults $(n=246)$ and young adults $(n=208)$. Then, 'Historical value' with adults $(n=249)$ and young adults $(n=189)$. The final criteria are 'Cooking method' with adults $(n=197)$ and young adults $(n=170)$. All criteria are being analysed and shown that there is a significant difference $(p<0.05)$ between adults (>36 years old) and young adults $(30-35$ years old).

Table 7 Criteria of the traditional food with Age

\begin{tabular}{|c|c|c|c|c|}
\hline \multirow[b]{2}{*}{ The criteria of the food heritage } & \multicolumn{3}{|c|}{ Age } & \multirow[b]{2}{*}{ P-value } \\
\hline & $30-35$ & $>36$ & Overall & \\
\hline Historical value & 189 & 249 & 438 & 0.000 \\
\hline Traditional value & 268 & 296 & 564 & 0.004 \\
\hline Authentic flavour & 208 & 246 & 454 & 0.002 \\
\hline Food presentation & 94 & 154 & 248 & 0.000 \\
\hline Variety & 64 & 128 & 192 & 0.000 \\
\hline Convenience & 30 & 98 & 128 & 0.000 \\
\hline Commonalities & 28 & 94 & 122 & 0.000 \\
\hline Originality & 225 & 279 & 504 & 0.000 \\
\hline Staple food ingredients & 82 & 189 & 271 & 0.000 \\
\hline Sensory properties & 72 & 160 & 232 & 0.000 \\
\hline Cooking method & 170 & 197 & 367 & 0.037 \\
\hline Food Innovation & 40 & 107 & 147 & 0.000 \\
\hline Technology & 25 & 101 & 126 & 0.000 \\
\hline Cross-culturing & 75 & 142 & 217 & 0.000 \\
\hline
\end{tabular}

\subsection{Discussion}

The demographic background plays a role in representing and defining a country, especially when dealing with the identification of food heritage and redefining it towards the national identity, in this context, in Malaysia. Previous literature showed that demographics play a role in identifying identities across cultures and countries as identification for marketing segment, food product, identity process theory and consumer definition (Ramli et al., 2016). 
Both age group, adult (>36 years old) and young adult (30-35 years old) gave a different opinion regarding food heritage definition except for 'traditional food'. Sebastia (2016) mentioned that the common belief in traditional food often invokes cultural heritage, in which involves traditional knowledge. The know-how shared and transmitted by word-of-mouth among small and big groups such as family, clan territory, country or geographical region covering several countries. Wahid et al. (2009) classified food heritage as classical and traditional foods which are prepared by all generation without changing its flavour, taste and familiar to the locals. Hence, traditional food tends to be well-recognised by all ages as the practice of imparting the knowledge of its preparation remains in current society. However, Hamzah et al. (2015) also stated that most youth knows on traditional food but do not acquire the respective preparation skills.

Traditional food listed under National Food Heritage is accepted as representative of Malaysian food as part of country Gastronomic Culture (Leong et al., 2012). It is indicated that young adults are more knowledgeable on foods that considered as heritage. However, Hairon, Zahari, Akbarruddin, \& Majid (2017) statement on young people's eating habits tends to try new things and avoiding mainstream food. Therefore, the young lean more towards convenient and conform to mainstream culture compare to the old. The continuous change is inevitable in the formation of social identity, especially among youth who undergo the most critical period in their lives. This phase of youth identity formation is associated with the greatest level of experimentation as well as openness to external influences. Today, the external influences are evident not just in the immediate social environment but also from the cyber world as evident in the term 'netizen' which is popular with young people (Ratnasingam, 2010). Young generation eating habits show a tendency to try new thing and to experience it with their friends, family, and peers (Hairon et al., 2017; Hamzah et al., 2015). Noor, Zakaria, Shahril, Hadi, \& Zahari (2013) state that age plays an essential role in knowledge and ability to provide relevant information. As for the older age group, they are committed to specific ways of life and generally more suspicious and resistant to new things. These past literature conflict with the findings. There would be other factors that influence the young adult awareness on food heritage such as education background, information finding such as electronic and printed media.

Media play an important role in gathering information from across the globe, which provides with a range of option that requires them to make choices based on their values and priorities (O'Kane, 2016). Most adults use electronic media to create or post their cultural heritage experiences whereas, for young adults, the heritage institution may need a precise tool and personal type of media to engage with the heritage (Amestoy, 2013) as youth have their cultural patterns and values which can be influenced by a variety form of mass media (Hamzah et al., 2015). The demand for "heritage, traditional and local" food is linked to a quest for authenticity (Sims, 2009). There is a disconnection of the young generation with their cultural background due to lack of communication and knowledge from the older generation about their cultural legacies and histories (Alden, 2011). To preserve food heritage, the involvement of young generation in preparation of traditional food is essential, which is possible through festivals and celebration with the guidance from the older generation especially in transferring knowledge and continuous practice (Noor, et al., 2013).

Food heritage is emphasised as part of the nation's intangible cultural heritage whereby the Department of National Heritage under the Ministry of Tourism and Culture Malaysia responsible for determining and registered intangible and tangible cultural heritage (Mustafa et al., 2013). It shows that food act as a marker or identity of individuals or community (Eum, 2008), especially food that is already recognised as heritage. Youth can be represented as the mediator of culture through sustaining heritage as well as an asset to preserve the heritage food from rapid globalisation (Hamzah et al., 2015).

\subsection{Conclusion}

The findings show that there is a difference between adults and young adults in answering food heritage awareness questions based on the definition of food heritage, the list of categories of food heritage, media information, authority, association and criteria for food heritage. All results show that adults ( $>36$ years of age) respond to and participate more in all questions than young adults (30-35 years of age). However, an exception is made for the list of categories of food heritage given that young adults have a more active response to these criteria compared to adults, as this may be due to the high use of electronic media by young adults in the search for information on the food heritage. However, it does not help young adults to respond correctly to the authority responsible for the endorsement of the National Food Heritage.

In general, the different awareness between young adults and adults can be used as a key factor for government or stakeholders to develop an appropriate mechanism for maintaining traditional food in the face of homogenising pressures from outside the world, such as globalisation. Using platforms such as the Internet and social networks that are popular with young adults in disseminating knowledge of local cuisine, and creating a channel that suits adult interests could build awareness of the nation's food heritage for both ages to strengthen the nation's identity.

\section{References}

Alden, D. (2011). A Fading Tradition: Design as a Portal to The Discovery of One's Own Cultural Heritage. Iridescent, 1(2), 64-73.

MD Ramli, A., Ahmad Sapawi, D. K., \& Mohd Zahari, M. S. (2020). The determinants of food heritage based on age in Klang Valley, Malaysia. Journal of Tourism, Hospitality \& Culinary Arts (JTHCA), 12(1), 1-16.

Amestoy, V. A. (2013). Demand for cultural heritage Handbook on the economics of cultural heritage: Edward Elgar Publishing

Bessiere, J. (1998). Local Development and Heritage: Traditional Food and Cuisine as Tourist Attractions in Rural Areas. Sociologia Ruralis, 38(21-34). 
Bortolotto, C., \& Ubertazzi, B. (2018). Foodways as Intangible Cultural Heritage. International Journal of Cultural Property, 25(4), $409-418$.

Choe, J. Y. J., \& Kim, S. S. (2018). Effects of tourists' local food consumption value on attitude, food destination image, and behavioral intention. International Journal of Hospitality Management, 71, 1-10.

Di Fiore, L. (2019). Heritage and food history. Food Heritage and Nationalism in Europe. London: Routledge, Taylor \& Francis Group.

Eum, I. (2008). A Study on Current Culinary Culture and Religious Identity in the Gulf Region. International Area Review, 11(2), 55-73.

Farahani, B. M., Abooali, G., \& Mohamed, B. (2012). George Town World Heritage Site: What We Have and What We Sell? Asian Culture and History, (2).

Graham, B. (2002). Heritage as knowledge: capital or culture? Urban studies, 39(5-6), 1003-1017.

Hairon, S., Zahari, M. S. M., Akbarruddin, M. N. A., \& Majid, H. N. A. (2017). Overview of Hipster food culture development in Malaysia. Journal of Tourism, Hospitality \& Culinary Arts, 9(2), 481-492.

Hamzah, H., Ab Karim, M. S., Othman, M., \& Hamzah, A. (2013). Dimensions of Authenticity in Malay Cuisine from Experts' Perspectives. Academic Journal of Interdisciplinary Studies, 2(3), 369.

Hamzah, H., Karim, M. S. A., Othman, M., Hamzah, A., \& Muhammad, N. H. (2015). Challenges in Sustaining the Malay Traditional Kuih among Youth. International Journal of Social Science and Humanity, 5(5), 472-478.

Jalis, M. H., Che, D., \& Markwell, K. (2014). Utilising local cuisine to market Malaysia as a tourist destination. Procedia-Social and Behavioral Sciences, $144,102-110$.

Kamaruddin, R., Osman, I., \& Pei, C. A. C. (2017). Customer expectations and its relationship towards public transport in Klang Valley. Journal of ASIAN Behavioural Studies, 2(4), 29-39.

Leong, Q. L., Othman, M., Mohd Adzahan, N., \& Ab. Karim, M. S. (2012). A Model of Malaysian Food Image Component: Toward Building a Sustainable Tourism Product. PERTANIKA Journal Social Sciences \& Humanities, 20(2), 299-315.

Mac Con lomaire, M. (2018). Recognising food as part of Ireland's intangible cultural heritage. Folk Life, 56(2), 93-115.

Mustafa, N. A., \& Abdullah, N. C. (2013). Preservation of cultural heritage in Malaysia: An insight of the National Heritage Act 2005. Paper presented at the Proceedings of International Conference on Tourism Development, February.

Negara, J. W. (2019). Perisytiharan warisan kebangsaan Kementerian Penerangan Komunikasi dan Kebudayaan. Malaysia: Jabatan Warisan Negara.

Noor, S. M., Zakaria, N. A., Shahril, N. M., Hadi, H. A., \& Zahari, M. S. M. (2013). Pulut Kuning in Malay Society: The Beliefs and Practices Then and Now. Asian Social Science, $9(7)$.

O'Kane, G. (2016). A moveable feast: Contemporary relational food cultures emerging from local food networks. Appetite, 105, $218-231$.

Peterson, P. E., \& Baez, R. J. (2013). Oral Health Surveys: Basic Methods (5 ed.). France: World Health Organization.

Ratnasingam, M. (2010). National Identity: A Subset of Social Identity? In Ethnic Relations and Nation Building: The Way Forward (pp. 3-34). Petaling Jaya, Selangor, Malaysia: Strategic Information and Research Development Center.

Ramli, A. M., Zahari, M. S. M., Halim, N. A., \& Aris, M. H. M. (2016). The Knowledge of Food Heritage Identithy in Klang Valley, Malaysia. Procedia - Social and Behavioral Sciences, 222, 518-527.

Schwartz, S. J. (2016). A New Identity for Identity Research. Journal of Adolescent Research, 20(3), 293-308.

Sébastia, B. (2016). Eating traditional food: politics, identity and practices Eating Traditional Food (pp. 15-33): Routledge

Shariff, N. M., Mokhtar, K., \& Zakaria, Z. (2008). Issues in the Preservation of Traditional Cuisines: A Case Study in Northern Malaysia. International Journal of the Humanities, 6(6).

Shariff, N. M., \& Zakaria, Z. (2011). Digital Mapping of Intangible Cultural Heritage: The Case of Traditional Foods. International Journal of the Humanities, 8

Sims, R. (2009). Food, Place And Authenticity: Local Food And The Sustainable Tourism Experience. Journal of Sustainable Tourism, 17(3), $321-336$.

Sompong, N., \& Rampai, N. (2015). Knowledge management of Thai local food on the route of northern tourism in Thailand. International Journal of Information and Education Technology, 5(9), 664.

UNESCO. (2008). World Heritage Information Kit. France: UNESCO World Heritage Center. Retrieved from http://whc.unesco.org.

Wahid, N. A. (2009). Heritage Food Tourism: Bahulu Attracts? Paper presented at the 2nd National Symposium on Tourism Research: Theories and Application, Universiti Sains Malaysia, Pulau Pinang. 